\title{
Androgen Secreting Steroid Cell Tumor of the Ovary Represented with Postmenopasal Bleeding and Extensive Hirsutism
}

\author{
Jadranka Georgievska $^{1 *}$, Vesna Antovska ${ }^{1}$, Neli Basheska $^{2}$, Natasha Aleksioska $^{1}$ \\ ${ }^{1}$ University Clinic of Gynecology and Obstetrics, Faculty of Medicine, Ss Cyril and Methodius University of Skopje, Republic \\ of Macedonia; ${ }^{2}$ Instiute of Radiotherapy and Oncology, Department of Histopathology and Clinical Cytology, Ss Cyril and \\ Methodius University of Skopje, Republic of Macedonia
}

\begin{abstract}
Citation: Georgievska J, Antovska V, Basheska $\mathrm{N}$, Aleksioska N. Androgen Secreting Steroid Cell Tumor of the Ovary Represented with Postmenopasal Bleeding and Extensive Hirsutism 1(1):93-98.

http://dx.doi.org/10.3889/oamjms.2013.019

Key words: hirsutism; steroid cell tumor; ovary; testosterone; laparoscopy.

"Correspondence: Dr. Jadranka Georgievska. Clinic of Gynecology and Obstetrics Vodnjanska 17, Skopje 1109, Republic Macedonia. E-Mail: jadrankageo@yahoo.com

Received: 22-Sep-2013; Revised: 26-Nov2013; Accepted: 27-Nov-2013; Online first: 03-Dec-2013

Copyright: ๑ 2013 Georgievska J. This is an open-access article distributed under the terms of the Creative Commons Attribution License, which permits unrestricted use, distribution, and reproduction in any medium, provided the original author and source are credited.

Competing Interests: The authors have declared that no competing interests exist.
\end{abstract}

\begin{abstract}
Introduction: Steroid cell tumors of the ovary present less than $0.1 \%$ of all ovarian tumors and belong in the group of sex cord-stromal tumors.

Case description: We present a case of 69-year-old woman investigated because of postmenopausal bleeding, a 5-year history of excessive hirsutism, baldness and acne. The evaluation revealed elevated serum testosterone, but ultrasound detected a $2 \mathrm{~cm}$-mass of the left ovary. The patient underwent hysterectomy and bilateral adnexectomy. The histopathology diagnosis was steroid cell tumor, not otherwise specified. Postoperative chemotherapy was administered at the discretion of the radio-oncologist. At the last follow-up 48 months after surgery, the hirsutism was completely resolved, the serum testosterone was within the normal range and there was no evidence of recurrence.
\end{abstract}

Conclusion: In adult patients with hirsutism and elevated serum testosterone a possibility of a presence of an ovarian steroid cell tumor should be considered. Surgery is the main treatment of such patients.

\section{Introduction}

Steroid cell tumors of the ovary account for less than $0.1 \%$ of all ovarian tumors [1]. These tumors may present at any age in association with interesting presentations related to the hormonal activity and virilizing properties of tumor. Hayes and Scully [2] reported 63 cases in patients ranging from 2 to 80 years of age. The subtype, not otherwise specified, is associated with androgenic changes in approximately one half of patients with this tumor [1]. In a series of 63 cases from Massachusetts General Hospital, 94\% of the tumors were found to be unilateral and $28.6 \%$ were malignant [3]. As most of these tumors are diagnosed at an early stage and do not recur or metastasize, little is known about their response to therapies such as chemotherapy or radiation [3].
We report the case of a virilizing ovarian tumor in a postmenopausal woman, which presented with recidivant postmenopausal metrorrhagia and evident hirsutism. The diagnosis of the tumor site was made using preoperative pelvic ultrasonography, quatitative measurement of testosterone levels in blood samples and laparoscopic visualization, thereby leading to hysterectomy with bilateral adnexectomy.

\section{Case Description}

This is the case of a 69-year-old woman, admitted at our University Clinic of Obstetrics and Gynecology in Mars 2008 because of a 5-year history of excessive hirsutism, baldness, acne and recurrent postmenopausal uterine bleeding since October 2005. 
She had had normal menstrual cycles since menarche and her last menstruation was 15 years ago. Her hirsutism had developed within the last 5 years and had become more severe within the last year. The patient did not report any alteration regarding her libido. She denied any changes in her voice and muscle mass. She had two children and two artificial abortions in her generative history. Her family history was unremarkable. She had not taken any hormones or had any previous surgeries. Because of a recurrent postmenopausal uterine bleeding she had three explorative curettages (in October 2005, in September 2006 and in February 2008). The histopathological analyses revealed only an atrophic endometrium.

Physical examination revealed a grade I obese woman (body mass index of $30.6 \mathrm{~kg} / \mathrm{m}^{2}$ ), with male pattern baldness i.e. parietal temporal baldness, facial skin acne, and marked hirsutism, i.e. a male pattern of coarser hair distribution in the beard region, anterior chest wall, abdomen and extremities (grade 15 of the Ferriman \& Gallwey score, normal < 9) (4). Her voice was feminine and her muscle mass was slightly enlarged. The systolic blood pressure was 160 $\mathrm{mmHg}$ and diastolic one $100 \mathrm{mmHg}$ and heart rate was $85 / \mathrm{min}$. There were no striae or bruises. The patient had no specific symptoms of Cushing's syndrome. No acanthosis nigricans was noted. The breasts were atrophic, without masses or galactorrhea. The abdominal palpation did not provide additional information.

Vaginal examination revealed mild clitoral enlargement. No adnexal mass was palpable. The cytology test of cervical smear revealed only atrophy with inflammation.

The transvaginal ultrasound examination of the ovaries, performed by two different gynecologists revealed a solid hyperechogenic mass into the structure of the left ovary, measuring $23 \times 18 \times 22 \mathrm{~mm}$ with moderate to significant vascularity. There was no ascites, retroperitoneal lymphadenopathy, adrenal gland enlargement, or liver metastasis. No pathological signs were detected on the $X$ ray examination.

The initial laboratory investigation revealed a normal blood cell count, electrolyte level and liver and renal function tests within normal range.

Cushing syndrome was ruled out by an overnight dexamethasone suppression test $(1 \mathrm{mg}-$ cortisol $<1.0 \mu \mathrm{g} / \mathrm{dL}$ ), primary hyperaldosteronism by the measurement of serum potassium $(4.3 \mathrm{mEq} / \mathrm{L})$ and aldosterone ( $3.3 \mathrm{ng} / \mathrm{dL})$.

In addition, hormone levels were evaluated. The serum levels of estradiol and follicle-stimulating hormone were into the normal ranges for postmenopause, thyroid-stimulating hormone was also in normal range, and sex hormone-binding globulin (SHBG) levels were at the lower limit of the normal range. The patient had high serum testosterone (17.3 nmol/l) (normal range: 0.19-2.67 $\mathrm{nmol} / \mathrm{l})$, which implied the diagnosis of a virilizing tumor. Serum dehydroepiandrosterone sulfate (DHEAS) and androstendion were normal, which argued against an adrenal source of testosterone. The increase in testosterone levels during human chorionic gonadotropin ( $\mathrm{hCG}$ ) administration (5000 $\mathrm{IU} / \mathrm{d}$ for 3 days) was consistent with the hypothesis of an ovarian virilizing tumor. The tumor marker CA-125, as well as beta-human chorionic gonadotropin (HCG) and alpha-fetoprotein were into the normal ranges.

An ovarian virilizing tumor, as a source of hypertestosteronemia was supposed and the patient was advised to undergo surgery. She underwent diagnostic laparoscopy, during which a sample from peritoneal washing was taken. It discovered only mature lymphocytes, but no malignant cells. The right ovary, womb and all peritoneal surfaces were normal. A yellow-coloured tumor measuring $2 \mathrm{~cm}$ was found in the left ovary. The final surgical procedure included hysterectomy with bilateral salpingo-oophorectomy.
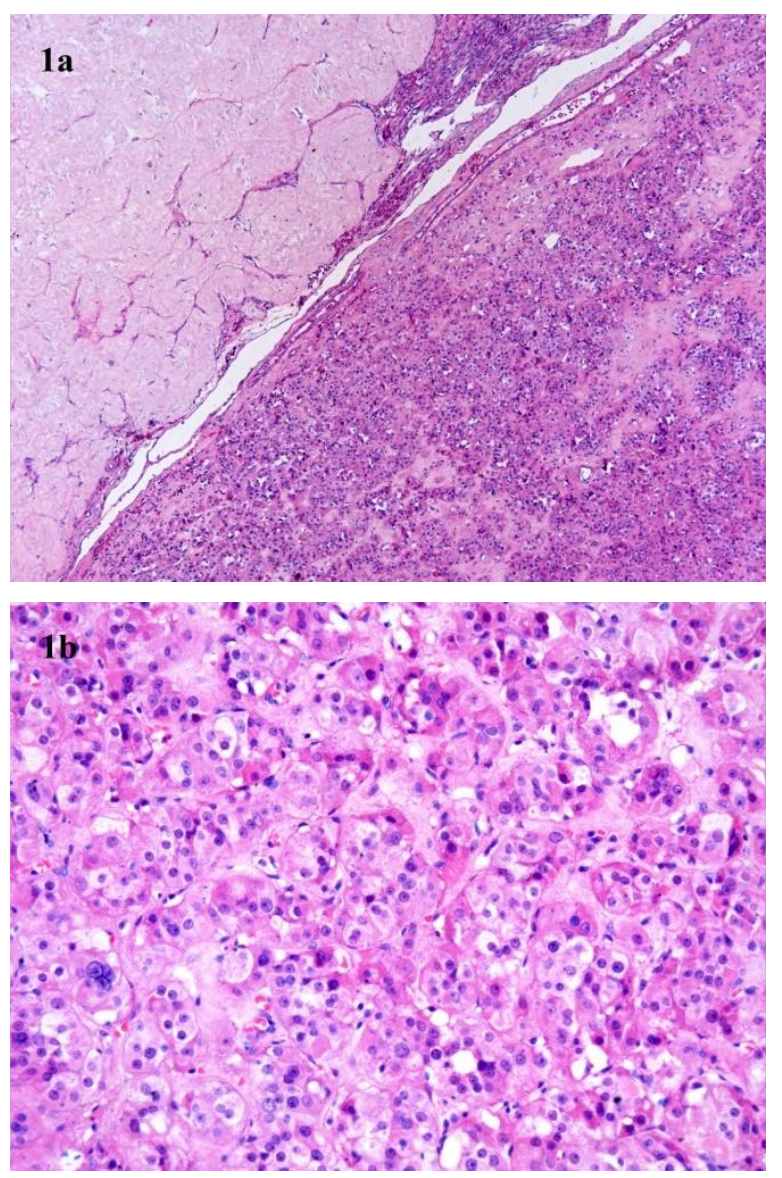

Figure 1: Steroid cell tumor not otherwise specified: low power view showing the tumor mass clearly separated from the normal ovarian cortex with corpora albicantia (1a, hematoxylin and eosin stain, original magnification: $x 50$ ); the high power shows variably sized, round to polygonal tumor cells, with granular, eosinophylic or less frequently more abundant vacuolated cytoplasm and round nuclei with prominent nucleoli (1b, hematoxylin and eosin stain, original magnification: $x 200$ ). 
Grossly the uterine corpus measured $5.5 \mathrm{x}$ $4.5 \times 4 \mathrm{~cm}$, and the dimensions of the uterine cervix were $4.2 \times 3 \times 1.4 \mathrm{~cm}$. A polypoid mass $13 \mathrm{~mm}$ in diameter was attached to the mucosa of the anterior uterine wall, while an intramural leiomyoma measuring $17 \mathrm{~mm}$ was dissected in the right uterine wall. Both adnexa were of normal size (right ovary: $3 \times 2 \times 1 \mathrm{~cm}$; left ovary: $3 \times 2.5 \times 1 \mathrm{~cm}$ ) and were externally unremarkable. A cut section of the left ovary showed a well circumscribed, yellowish-brown solid nodule 17 $\mathrm{mm}$ in diameter.
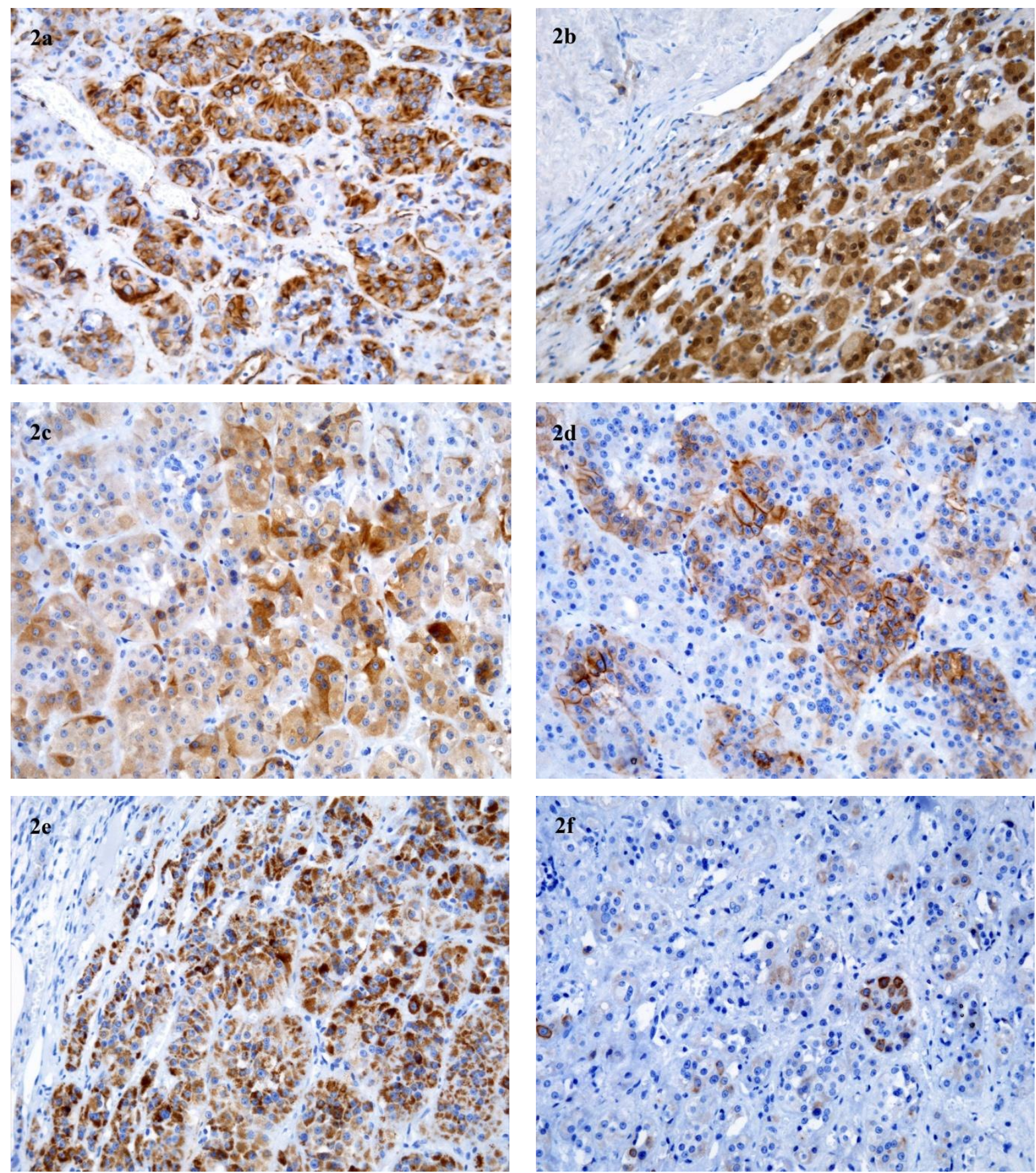

Figure 2: Immunohistochemical results: the neoplastic cells were diffusely immunoreactive for vimentin (2a, diaminobenzidine, x200), calretinin (2b, diaminobenzidine, x200), alpha-inhibin (2c, diaminobenzidine, x200), CD56 (2d, diaminobenzidine, x200).and melan A (2e, diaminobenzidine, x200), and focally for pan-cytokeratin (2f, diaminobenzidine, $x 200)$.

Histopathology confirmed a $17 \mathrm{~mm}$ steroid tumor of the left ovary localized next to the ovarian hilum. Superiorly the mass was covered by a $1-7 \mathrm{~mm}$ thick crescent of ovarian cortex with corpora albicantia and a number of arterioles with thick hyaline walls
(Figure 1a). The tumor was unencapsulated, and composed of tumor cells arranged diffusely or in some other areas in small nests and clusters, separated by scant, delicate or focally more abundant intervening fibrous stroma with hyalinization. Tumor cells were 
round to polygonal, with distinct cell membranes. Most of the cells were medium-sized and had finely granulated, eosinophilic cytoplasm. Less frequently the cells were large in size with vacuolated cytoplasm (Figure 1b). Some of these cells contained small lipid droplets as demonstrated by oil-red $O$ stain. Intracytoplasmic lipochrome pigment was also present in a small number of cells. The nuclei were round and centrally placed, frequently with prominent small single nucleoli. Crystals of Reinke were not observed. No nuclear atypia was found and at most one mitosis per 10 high power fields (x400) was counted. There were no foci of necrosis or hemorrhage present. Immunohistochemistry staining demonstrated that the tumor cells were diffusely positive for vimentin, alphainhibin, calretinin, melan A, CD99, and CD56, and focally positive for pan-cytokeratin (Figure 2a-f). These findings were consistent with a steroid cell tumor, not otherwise specified of the left ovary which lacked the unfavorable histological features associated with malignant behavior.

In the right ovary only corpora albicantia as well as mesonephric remnants in the medulla were present. Histopathological examination of the sections taken from the uterus revealed that the endometrium was atrophic, as well as the presence of a senile endometrial polyp, small intramural leiomyoma and chronic inflammation with rare ovula Nabothi in uterine cervix.

The early postoperative period was regular and patient was dismissed from the hospital on the seventh postoperative day. An additional chemotherapy was administrated at the University Clinic of Radiotherapy and Oncology, at the discretion of radio oncologist (four cycles of Carboplatin à 500 $\mathrm{mg} / \mathrm{m}^{2}$ ). At the first follow-up controls (3 months after the operation), the hirsutism was completely resolved, the serum testosterone was into the normal range $(0.5$ $\mathrm{nmol} / \mathrm{l})$ and the androgenic alopecia almost completely reversed. The patient is being followed up with regular measurement of serum testosterone and pelvic ultrasound examination every 6 months for early diagnosis of disease recurrence. At the last follow-up 48 months after surgery she was in good condition, the hirsutism and alopecia were completely resolved, and no relapse of the disease was found.

\section{Discussion}

The diagnosis of ovarian virilizing tumors can be difficult in women of any generative age, because the size of such tumors is often too small to allow detection by ultrasound or radiological examination [5]. Many histological tumor types have been described, and different classifications have been proposed. The most frequent type is the Sertoli-Leydig cell tumor arrhenoblastoma, which is observed in premenopausal women. Eighty percent of such tumors result in hyperandrogenism [6]. They are small tumors (less than $4 \mathrm{~cm}$ in diameter), unilateral in more than $95 \%$ of cases, with excellent prognosis because almost all of them are benign. Hilar Leydig cell tumors are more often observed in postmenopausal women and are gonadotropin dependent. The rare hilar nonLeydig cell tumors that are diagnosed in younger women belong to another histological type classified as nonspecific tumors. Only $50 \%$ of them are associated with hyperandrogenism, and $20-40 \%$ are malignant [7]. However, when located in the hilum, they are more likely to be benign, and a small size is a criterion for better prognosis. Regnier et al. [8] reported a very rare case of simultaneous presence of Leydig cell tumor of the ovary and adrenal incidentaloma in a 41-year-old female patient, referred for evaluation of hirsutism that had increased within the previous 3 years.

The classical microscopic findings of steroid cell tumors include cells which can be diffusely arranged or arranged into nests, clusters, cords and columns. Steroid cell tumors lack crystals of Reinke. Immunohistochemistry helps in the distinction between steroid cell tumors of the ovary and other primary or metastatic ovarian neoplasms [9]. There are three subtypes of these tumors: stromal luteoma, Leydig cell tumor (hilus and non-hilus cell type) and steroid cell tumor (not otherwise specified). The steroid cell tumor (not otherwise specified) is larger and may secrete adrenal cortex steroid hormones that can induce hypercortisolism, also known as Cushing syndrome [10]. Nevertheless, pathologically benign steroid cell tumors can behave in a clinically malignant fashion. Therefore, about $20 \%$ of patients develop metastatic lesions in peritoneal cavity, and rarely at distant sites. Their primary treatment is surgical extirpation of the primary lesion, but there are no reports of effective radiation or chemotherapy because of the rarity of this tumor. In recent years, the use of gonadotropin releasing hormone $(\mathrm{GnRH})$ agonists promises in non-surgical cure with suppression effect on hormone secretion and leading to apoptosis of cells, as well.

Hirsutism, which can be defined as excessive growth of androgen-dependent sexual hair, is one of the manifestations of these tumors, as a result of increased androgen production of the tumor tissue [11]. It can be isolated or associated with other signs of increased androgen levels, such as: menstrual disturbances, acne, deepening of the voice, increase in muscle mass, clitoromegaly, breast hypotrophy and frontoparietal balding.

Especial difficulties arise in the differential diagnosis of steroid cell tumors from other possible causes of hirsutism in perimenopause. Apart of iatrogenia and steroid cell ovarian tumors, other possible causes of hirsutism in perimenopause could be nonclassical congenital adrenal hyperplasia, ovarian hyperthecosis or adrenal tumors. This differential diagnosis is important, since 
adrenal/ovarian tumors can be life-threatening conditions and deserve surgical treatment. On the other hand, the ovarian hyperthecosis, as a part of the HAIR-AN syndrome, is a result of hyperplasia/ luteinization of the cortical stroma. Its basic physiological mechanism during the premenopuausal age is a presence of severe insulin resistance, while in the postmenopause, it is due to the continuous stimuli of elevated gonadotropins [12, 13]. In postmenopause, the hyperandrogenic syndrome is unrelated to insulin resistance, but it is result of continuous increasing levels of luteinizing hormone [14]. The hallmark of this syndrome is an increase in bilateral ovarian volume, although unilateral increase in ovarian volume has been described [15]. Only a few women with hyperthecosis have been treated with a gonadotropin releasing hormone $(\mathrm{GnRH})$ agonist, but all had a substantial decrease in serum androgen concentrations.

Hayes and Scully [2] have identified five pathologic features of the steroid cell tumors associated with malignancy: 1) more than two mitoses per high-power field; 2) necrosis; 3) size of $7 \mathrm{~cm}$ or larger; 4) hemorrhage; 5) grade 2 or 3 of nuclear atypia. In our case, none of them was present. The characteristic pattern of immunohistochemistry staining for inhibin, calretinin, melan A, CD99, and CD56, along with the positivity for and vimentin and anti-human cytokeratin, as well as and distinct cell borders with the absence of Reinke's crystals are crucial for diagnosis [9]. All abovementioned patterns were present in our case.

Choudhary et al. [16] reported a case of steroid cell tumor in 50-year-old women with hirsutism, clitoromegaly and frontal baldness, elevated serum testosterone level and normal DHEA-sulfate, which is very similar to our case.

The presence of an adrenal tumor could be another cause for hirsutism in postmenopausal age. In all androgen-producing ovarian tumors, serum testosterone level is elevated in conjunction with normal or mildly elevated serum DHEAS levels, but the increased dehydroepiandrosterone sulphate levels are often associated with adrenal tumors [17]. A dexamethasone suppression test may be useful to help distinguish between ovarian and adrenal sources of androgens. We had also applied this test in the preoperative investigation.

Our case is interesting because of the recurrent episodes of postmenopausal metrorrhagia required explorative curettage. The ultrasound investigation revealed a small solid tumor $2 \mathrm{~cm}$ in diameter of the left ovary, in spite of the fact that the tumor was nonpalpable. The presence of signs of virilization and hypertestosteronemia led us to right diagnosis and adequate treatment.

In recent years attempts have been made with the use of gonadotropin releasing hormone $(\mathrm{GnRH})$ analogues for suppression of secretion and non-surgical cure. These approaches have been tried especially in non-operable cases or recurrent disease. Therefore, at best, these treatments can be considered experimental at the present time. Further insight into the nature, biology and behavior of these tumors may change the gold standard of treatment from surgical extirpation to medical management over time.

In women with recent-onset or rapidly progressive hirsutism, with or without normal menstrual cycles, measurement of testosterone levels and detailed pelvic ultrasound examination are mandatory to screen for virilizing tumors. Our case was interesting because of the presentation with recurrent postmenopausal metrorrhagia and signs of virilization due to hypertestosteronemia which helped us to make a correct diagnosis and treatment of the patient. The primary treatment is still surgical extirpation, because of the fact that some of these tumors have malignant potential. In some cases, an additional oncological treatment could be recommended.

\section{References}

1. Young $\mathrm{RH}$, Shully RE. Steroid cell tumors of the ovary. In: Fox $H$, Wells $M$, editor. Obstetric \& Gynecological Pathology. Spain, Churchill Livingstone, 2003. pp. 845-56.

2. Hayes MC, Scully RE. Ovarian steroid cell tumors [not otherwise specified]: a clinicopathological analysis of 63 cases. Am J Surg Pathol. 1987;11:835-45.

3. Scully RE, Young RH, Clement PB. Tumors of the Ovary, Maldeveloped Gonads, Fallopian Tube, and Broad Ligament. Washington, DC: Armed Forces Institute of Pathology. Steroid cell tumors, 1996: pp. 227-38.

4. Ferriman D, Gallwey JD. Clinical assessment of body hair growth in women. J Clin Endocrinol Metab. 1961; 21:1440-7.

5. Pugeat $\mathrm{M}$, Mirakian $\mathrm{P}$, Dutrieux-Berger $\mathrm{N}$ et al. Androgensecreting ovarian neoplasm. In: Azziz R, Nestler JE, Dewailly $\mathrm{D}$, eds. Androgen excess disorders in women. Philadelphia, New York: Lippincott-Raven, 1997:555-568.

6. Monteagudo A, Heller D, Husami $\mathrm{N}$ et al. Ovarian steroid cell tumors: sonographic characteristics. Ultrasound Obstet Gynecol. 1997; 10(4):282-288.

7. Young $\mathrm{RH}$. Ovarian tumors other than those of surface epithelial-stromal type. Hum Pathol. 1991; 22(8):763-75.

8. Regnier C, Bennet A, Malet D et al. Intraoperative testosterone assay for virilizing ovarian tumor topographic assessment: report of a Leydig cell tumor of the ovary in a premenopausal woman with an adrenal incidentaloma. J Clin Endocrino Metab. 2002; 87(7):3074-7.

9. Jones MW, Raj H, Dabbs DJ, Carter GJ. Immunohistochemical profile of steroid cell tumor of the ovary: A study of 14 cases and a review of the literature. Int J Gynecol Pathol. 2010; 29(4):315-20.

10. Saida T, Tanaka YO, Minami M. Steroid cell tumor of the ovary, not otherwise specified: CT and MR findings. AJR AJR Am J Roentgenol. 2007; 188(4): W393-4.

11. Rosenfield RL. Pilosebaceous physiology in relation to hirsutism and acne. J Clin Endocrinol Metab. 1986;15:341-62.

12. Khan CR, Flier JS, Bas RS et al. The syndromes of insulin resistance and acanthosis nigricans. Insulin-receptor disorders 
in man. N Engl J Med. 1976;294(14):739-45.

13. Goldman JM, Kapadia LJ. Virilization in a postmenopausal woman due to ovarian stromal hyperthecosis. Postgrad Med J. 1991;67(785):304-6.

14. Krug E, Berga SL. Postmenopausal hyperthecosis: functional dysregulation of androgenesis in climacteric ovary. Obstet Gynecol. 2002; 99(5 Pt 2):893-7.

15. Farber M, Madanes A, O'Briain DS et al. Asymmetric hyperthecosis ovarii. Obstet Gynecol. 1981;57(4):521-5.

16. Choudhary SV, Banode PJ, Bhake A et al. Hirsutism with virilization in a postmenopausal woman due to a rare ovarian steroid cell tumor. Indian J Dermatol Venereol Leprol. 2010; 76(2):216.

17. Nardo LG, Ray DW, Laing I et al. Ovarian Leydig cell tumor in a peri-menopausal woman with severe hyperandrogenism and virilization. Gynecol Endocrinol. 2005; 21(4):238-241. 